\section{Suicide and multiple sclerosis: an epidemiological investigation}

Elsebeth Nylev Stenager, Egon Stenager, Nils Koch-Henriksen, Henrik Brønnum-Hansen, Kay Hyllested, Knud Jensen, Unni Bille-Brahe Research Unit, Odense University, Odense EN Stenager K Jensen

Clinical

Neuropsychiatric Research Unit, Odense University and Department of Neurology, Odense University Hospital E Stenager

The Danish Multiple Sclerosis Registry, Rigshospitalet, Copenhagen N Koch-Henriksen K Hyllested

The Danish Institute of Clinical Epidemiology, Copenhagen H Brønnum-Hansen

Clinical Institute, Department of Psychiatry, Odense University, Odense, Denmark

U Bille-Brahe

Correspondence to: Dr Stenager, Department of Neurology, Odense University Hospital, 5000 Odense, Denmark.

Received 4 July 1991 and in revised form 20 August 1991. Accepted 28 August 1991

A number of studies have shown that patients with multiple sclerosis (MS) often have mental disorders. ${ }^{1}$ American, Israeli, and Danish studies show that $12-25 \%$ of the MS patients examined have been admitted to a psychiatric department or received psychiatric outpatient treatment at or after the time of onset of the disease. $^{2}$

The mental disorder MS patients most frequently present with is depression. Forty to fifty per cent of MS patients will experience depression during the course of the disease. ${ }^{134}$ A study of 117 representatively selected MS patients ${ }^{5}$ showed that depression was significantly associated with exacerbation of the physical or cognitive symptoms of the disease. Patients were examined for depressive symptoms using the Beck Depression Inventory. Other investigations have shown a correlation between depression and MS. ${ }^{6}$ In a Danish follow up study, ${ }^{7}$ depression and chronic disorders were found to be predictors of suicide. A correlation between chronic somatic disorders, for example, cancer and epilepsy, and increased risk of suicide has been found. ${ }^{8}$

The lifetime risk of suicide in those who have suffered from a depression has been estimated at $15 \% .{ }^{10}$ As the frequency of depression in

\begin{abstract}
Clinical Institute,
Department of Psychiatry and Neuropsychiatric

Abstract

In a nationwide investigation the risk of death by suicide for patients with multiple sclerosis (MS) was assessed using records kept at the Danish Multiple Sclerosis Registry (DMSR) and the Danish National Register of Cause of Death. The investigation covers all $M S$ patients registered with DSMR with an onset of the disease within the period $1953-85$, or for whom MS was diagnosed in the same period. Fifty three of the 5525 cases in the onset cohort group committed suicide. Using the figures from the population death statistics by adjustment to number of subjects, duration of observation, sex, age, and calendar year at the start of observation, the expected number of suicides was calculated to be nearly 29 . The cumulative lifetime risk of suicide from onset of MS, using an actuarial method of calculation, was $1.95 \%$. The standard mortality ratio (SMR) of suicide in MS was $\mathbf{1 \cdot 8 3}$. It was highest for males and for patients with onset of MS before the age of 30 years and those diagnosed before the age of 40. The SMR was highest within the first five years after diagnosis.
\end{abstract}

MS patients is high, a greater number of suicides in MS patients could be expected. The few studies on the subject which are available, are all based on a small number of cases.

Müller, ${ }^{11}$ McAlpine et $a l,{ }^{12}$ and Schwartz and Pierron ${ }^{13}$ did not find a greater number of suicides among MS patients. Kurtzke et $a l^{14}$ found only one suicide out of 122 deaths in MS patients. In an Israeli investigation ${ }^{15}$ the frequency of suicide in MS patients was 14 times that of the background population. Sadovnick et al ${ }^{16}$ found 13 suicides out of 80 deaths among MS patients. In a Swedish study of 416 suicides, ${ }^{17}$ two were found to be MS patients. A pilot study on the frequency of suicide in MS patients for the period 1973-85 in the county of Funen, Denmark ${ }^{18}$ showed that five of 56 deaths were due to suicide. The suicides occurred within a few years of the diagnosis or in connection with an attack or progression of the disease.

The purpose of this study was to estimate the risk of suicide for MS patients in Denmark, compared with the background population, and to establish whether the risk of suicide is related to onset or diagnosis of the disease.

\section{Material and methods}

The study is based on entries recorded at the Danish Multiple Sclerosis Registry (DMSR) ${ }^{19}$ and the Danish National Registry of Cause of Death.

The DMSR was established following Hyllested's nationwide prevalence survey ${ }^{20}$ and the registration of incident cases of MS has been continued since 1948. The DMSR receives discharge notes from all Danish neurological departments on all suspected or diagnosed MS patients. Additional sources include the National Patient Registry, the National Registry of Cause of Death, and the National Disablement Insurance Court. At the DMSR all case reports, submitted since 1948, have been reviewed by the authors $(\mathrm{NKH}$, $\mathrm{KH})$ attached to the DMSR. They have been classified according to diagnostic criteria based on those of Allison and Millar, ${ }^{21}$ as reported by McAlpine, ${ }^{12}$ and further modified to include laboratory and paraclinical data. ${ }^{19}$ Cases, not fulfilling the diagnostic criteria, were discarded unless the diagnosis was verified by necropsy examination. The time of diagnosis refers to the time when the diagnosis was made. It was not possible to estimate when the patient was told. The calendar year of onset of disease was assessed retrospectively based on the case report and available clinical information. 
Table 1 Observed and expected number of suicides and the suicide Standard Mortality Ratios (SMR) in relation to age at onset in 5525 cases of $M S$

\begin{tabular}{|c|c|c|c|c|c|}
\hline \multirow[b]{2}{*}{ Sex } & \multirow[b]{2}{*}{ Age at onset (years) } & \multicolumn{2}{|c|}{ Number of suicides } & \multirow[b]{2}{*}{$S M R$} & \multirow[b]{2}{*}{$95 \%$ Confidence interval } \\
\hline & & Observed & Expected & & \\
\hline $\begin{array}{l}\text { Male } \\
\text { Total }\end{array}$ & $\begin{array}{l}\leqslant 30 \\
>30\end{array}$ & $\begin{array}{l}13 \\
19 \\
32\end{array}$ & $\begin{array}{l}4 \cdot 76 \\
11 \cdot 44 \\
16 \cdot 2\end{array}$ & $\begin{array}{l}2.73 \\
1.66 \\
1.98\end{array}$ & $\begin{array}{l}1.45-4.67 \\
1.0-2.59 \\
1.35-2.79\end{array}$ \\
\hline $\begin{array}{l}\text { Female } \\
\text { Total } \\
\text { Overall total }\end{array}$ & $\begin{array}{l}\leqslant 30 \\
>30\end{array}$ & $\begin{array}{r}5 \\
16 \\
21 \\
53\end{array}$ & $\begin{array}{r}3 \cdot 29 \\
8 \cdot 82 \\
12 \cdot 74 \\
28 \cdot 94\end{array}$ & $\begin{array}{l}1.28 \\
1.81 \\
1.65 \\
1.83\end{array}$ & $\begin{array}{l}0.41-2.98 \\
1 \cdot 04-2.94 \\
1 \cdot 37-2 \cdot 42 \\
1.37-2.40\end{array}$ \\
\hline
\end{tabular}

Completeness and validity of the DMSR has been estimated to be about $90 \% .^{19}$

All deaths in Denmark have been registered with the Registry of Cause of Death since 1952. Actual and underlying causes of death noted in the death certificate are recorded. All deaths that are not due to natural causes (that is, accidents, crimes, suicide), are reported to the police and to the county medical officer. After their investigations, cause of death is registered. In a previous study the validity of Danish suicide statistics was assessed and it was concluded that the reliability was high. ${ }^{22}$

Two analyses were carried out in this study namely, 5525 cases with onset of MS within the period 1952-85, and 6088 cases given a diagnosis within the period. The two series are not identical although they overlap, because in most cases a number of years elapse between the time of onset and diagnosis.

The standard mortality ratio (SMR) for suicide is the ratio between the observed number of suicides among the MS patients and the expected number of suicides, calculated from the background population for age and sex specific risk of suicide, and adjusted to the patient series for the calendar year at the start of observation.

\section{Results}

A total of 5525 patients with onset of MS between 1953 and 1985 were listed in the DMSR, 3191 females and 2334 males; 1444 patients had died by the end of 1985 . Of these, 53 had committed suicide ( 21 female and 32 male). The cumulative lifetime risk of suicide from the time of onset was nearly $2 \%$. The total number of expected suicides, calculated from the frequency of suicide in the background population was $28 \cdot 9$. SMR was $1 \cdot 83$.

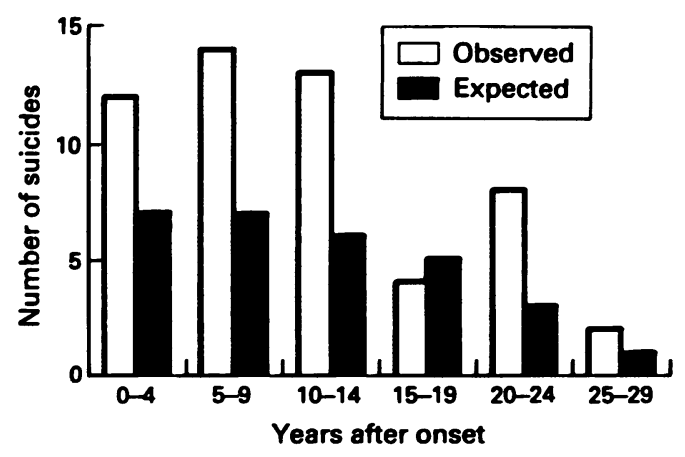

Figure 1 Suicide in relation to onset of MS.
Suicide and age at onset of $M S$

Male patients with onset of MS up to and including the age of 30 years were at highest relative risk of suicide $(S M R=2.73)$ (table 1$)$, followed by females with an onset after the age of 30 years $(S M R=1 \cdot 81)$. The lowest relative risk of suicide was seen in females with an onset up to and including the age of 30 years $(\mathrm{SMR}=1 \cdot 28, \mathrm{~ns})$ and males with onset after the age of 30 years (SMR $=1.66), p=0.05)$. The figures are listed in table 1 together with the $95 \%$ confidence intervals. Figure 1 shows that the SMR was highest in the 15 years succeeding the onset.

\section{Suicide and age at diagnosis of $M S$}

This analysis covered the 6088 cases in which the MS diagnosis was established in the period 1953-85. Of these, 3514 were female and 2574 male; 1839 patients had died before the follow up at the end of $1985 ; 58$ had committed suicide ( 22 females and 36 males). The patient series was divided into two groups according to age at time of diagnosis. SMR for suicide was highest in males and females given the diagnosis up to and including the age of 40 , $3 \cdot 12$ and $2 \cdot 12$ respectively. For men and women given the diagnosis after the age of 40 years, the SMR was just 1.52 and 1.51 , respectively, which is not significantly different. These figures with $95 \%$ confidence limits are listed in table 2.

Figure 2 shows that most of the suicides took place within five years of the diagnosis. When compared with figure 1 , it is clear that the time of suicide is more related to the time of diagnosis than to the time of onset. Figure 3 shows the distribution of age at the time of suicide.

\section{Discussion}

A number of cases with onset of MS within the study period were not yet listed in the DMSR at follow up on 31 December 1985 because of the long latency period occasionally seen between the onset of MS and the establishment of the diagnosis. As cases with a long latency period probably have a more benign course of the disease, the DMSR may be slightly overrepresented with cases of rapid progression. If such patients have a greater tendency towards suicide, the overall risk could be slightly overestimated.

Conversely, should the suicide frequency in new cases be high already before the diagnosis, the risk could be underestimated, as such cases 
Table 2 Observed and expected number of suicides and the suicide Standard Mortality Ratios (SMR) in relation to age at diagnosis in 6088 cases of MS

\begin{tabular}{|c|c|c|c|c|c|}
\hline \multirow[b]{2}{*}{ Sex } & \multirow[b]{2}{*}{ Age at diagnosis (years) } & \multicolumn{2}{|c|}{ Number of suicides } & \multirow[b]{2}{*}{$S M R$} & \multirow[b]{2}{*}{$95 \%$ Confidence interval } \\
\hline & & Observed & Expected & & \\
\hline $\begin{array}{l}\text { Male } \\
\text { Total }\end{array}$ & $\begin{array}{l}\leqslant 40 \\
>40\end{array}$ & $\begin{array}{l}25 \\
11 \\
36\end{array}$ & $\begin{array}{r}8 \cdot 02 \\
7 \cdot 23 \\
15 \cdot 25\end{array}$ & $\begin{array}{l}3 \cdot 12 \\
1.52 \\
2 \cdot 36\end{array}$ & $\begin{array}{l}2 \cdot 01-4 \cdot 6 \\
0.76-2 \cdot 72 \\
1 \cdot 65-3 \cdot 27\end{array}$ \\
\hline $\begin{array}{l}\text { Female } \\
\text { Total } \\
\text { Overall total }\end{array}$ & $\begin{array}{l}\leqslant 40 \\
>40\end{array}$ & $\begin{array}{r}13 \\
9 \\
22 \\
58\end{array}$ & $\begin{array}{c}6 \cdot 14 \\
5 \cdot 96 \\
12 \cdot 1 \\
27 \cdot 35\end{array}$ & $\begin{array}{l}2 \cdot 12 \\
1.51 \\
1 \cdot 82 \\
2 \cdot 12\end{array}$ & $\begin{array}{l}1 \cdot 13-3 \cdot 62 \\
0 \cdot 69-2 \cdot 87 \\
1 \cdot 14-2 \cdot 75 \\
1 \cdot 61-2 \cdot 74\end{array}$ \\
\hline
\end{tabular}

would not be registered in the DMSR. The number is probably quite small, as none of 31 MS cases without a clinical diagnosis, but recognised and notified to the DMSR as a result of necropsy examination, had died from suicide.

Certain forms of suicide are open to misclassification: a suicide by self injury could be mistaken for an accident, and self poisoning for natural death in a chronically ill person. If this risk of misclassification is greater for MS patients than for the background population, it may lead to an under estimation of the suicide rate. The net effect of these hypothetical biases is, however, considered to be negligible.

Half of the suicides took place within five years of the diagnosis. This finding is consistent with an earlier study ${ }^{18}$ based on case reports, indicating that MS patients committed suicide within a few years of the diagnosis or in conjunction with exacerbation of the disease.

Our study shows that the risk was highest among the youngest patients and especially among males. Part of the explanation may be that they have not yet been able to establish a network of support. They may often be suffering from the burden of not being able to fulfil

Figure 2 Suicide in relation to diagnosis of MS.

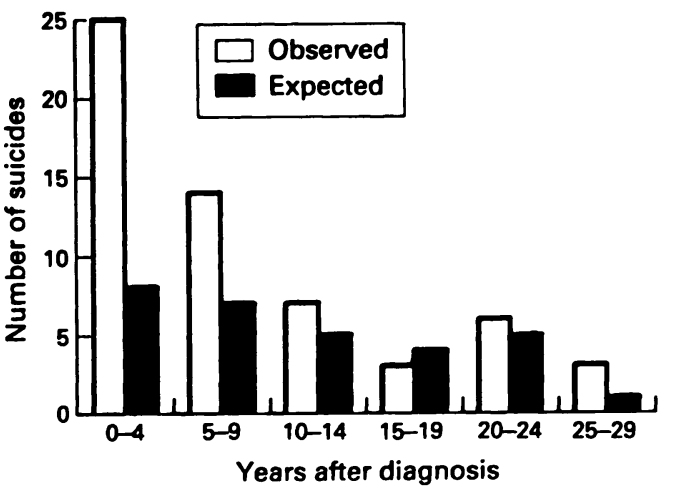

Figure 3 Age at time of suicide in MS patients.

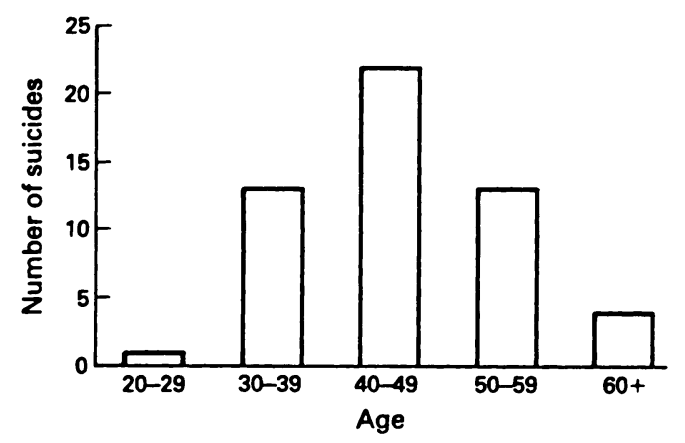

ambitions of education, job, and raising a family. Patients with onset of the disease in later life are more likely to have accomplished some of their ambitions and therefore able to benefit from the protection of a better social network. As the median age after the MS diagnosis is about 30 years, ${ }^{23}$ it is vital that preventive measures are initiated to avert suicide.

In an investigation of psychosomatic symptoms of MS patients, ${ }^{24}$ it was established that at least three periods in the course of the disease were associated with increased risk of depression: (a) The prediagnostic period; (b) The time following the diagnosis, and (c) Periods of progressing disability. This study confirms this pattern partly, as about half of the suicides were committed within five years of diagnosis. Prophylactic measures should be initiated particularly in that period. A study to elucidate the detailed circumstances of the 58 suicides is under preparation.

Fifty eight suicides in a nationwide patient series ranging over more than 30 years may be regarded as a small number, bearing in mind that 28 could have been expected to commit suicide even if they had not had MS. Suicide, however, is an extreme solution for the patient and may only be the tip of the iceberg. An additional number of the MS patients may have suffered from serious depression because of their disease.

When the diagnosis of MS is made, it is important that the physician recognises crisis reactions in the patient and intervenes accordingly if necessary with psychological support. In periods of progression of the disease it is important that close contact is maintained with the patient and the family, and help extended when adjustment of demands to the reduced capabilities of the patient is called for. ${ }^{25}$ The regional advice centres of the multiple sclerosis associations could, in this phase, provide a useful supplement to neurological outpatient services.

The Danish Multiple Sclerosis Registry is financially supported by the Danish Multiple Sclerosis Society. This study has been financially supported by the Rockwool Foundation in Denmark.

We thank Sheila Hauge for proof reading. The study was presented at the XVI Congress of the International Association for Suicide Prevention, Hamburg, September 1991.

1 Stenager E, Knudsen L, Jensen K. Multiple sclerosis and mental disorders. Semin Neurol 1990;10:254-61.

2 Stenager E, Jensen K. Multiple sclerosis: correlation of psychiatric admissions to onset of initial symptoms. Acta Neurol Scand 1988;77:414-7. 
3 Schiffer RB. The spectrum of depression in multiple sclerosis: an approach for clinical management. Arch sclerosis: an approach

4 Minden SL, Orav J, Reich P. Characteristics and prediction of depression in multiple sclerosis. In: Jensen $K$, Knudsen $\mathrm{L}$, Stenager E, Grant I, eds. Mental disorders and cognitive deficits in multiple sclerosis. London: John Libbey \& $\mathrm{Co}$, 1989:129-35. 5 Stenager E, Kinudsen L, Jensen K. Correlation of Beck Scale and Cognitive Functioning in Multiple Sclerosis. In: Jensen K, Knudsen L, Stenager E, Grant I, eds. Mental disorders and cognitive deficits in multiple sclerosis. London: John Libbey \& Co, 1989:147-51.

6 Whitlock FA. The neurology of affective disorder and suicide. Aust N Z f Psych 1982;16:1-12.

7 Nielsen B, Wang AG, Bille-Brahe U. Attempted suicide in Denmark IV. A five year follow-up. Acta Psychiatr Scand Denmark IV. A

8 Stenager EN, Jensen K, Billie-Brahe U. Kræft og selvmord. En litteraturoversigt. Ugeskr Laeger 1991;153:764-9.

9 Barraclough MM. The suicide rate of epilepsy. Acta Psychiatr Scand 1987;76:339-45.

10 Sainsbury P. Depression Suicide and Suicide Attempts. In: Roy A, ed. Suicide. Baltimore: Williams \& Wilkins Company, 1986:73-88.

11 Müller $R$. Studies on dissminated sclerosis with special reference to symptomatology course and prognosis. Acta Med Scand 1949;133:122.

12 McAlpine D, Lumsden CE, Acheson ED. Multiple Sclerosis. $A$ reappraisal. 2 ed. Baltimore: Williams \& Wilkins Company, 1972:179-84.

13 Schwartz ML, Pierron $M$. Suicide and fatal accidents in Multiple Sclerosis. Omega 1972;3:291-3.

14 Hashimoto S, Paty DW. Multiple Sclerosis. Dis Mon
1985;9:519-89.

15 Kahana E, Leibowitz U, Alter M. Cerebral Multiple Sclerosis̀. Neurology 1971;21:1179-85.

16 Sadovnick AB, Ebers GC, Paty DW, et al. Causes of death in multiple sclerosis. Can ₹ $\mathcal{f}$ Neurol Sci 1985;12:189.

17 Stennsman R, Sundqvist-Stennmann UB. Physical disease and disability among 416 suicide cases in Sweden. Scand f Soc Med 1988;16:149-53.

18 Stenager EN, Stenager E, Jensen K. Suizid bei Patienten mit Multipler Sclerose. In: Wedler H, Müller HJ, eds. Krankheit und Suizid. Regensburg: Roderer Verlag 1991;171-6.

19 Koch-Henriksen N, Hyllested K. Epidemiology of multiple sclerosis: incidence and prevalence rates in Denmark 1948-64 based on the Danish Multiple Sclerosis registry. Acta Neurol Scand 1988;78:369-80.

20 Hyllested K. Disseminated sclerosis in Denmark: prevalence and geographical distribution (Thesis). Copenhagen: J. Jorgensen \& Co., 1956.

21 Allison RS, Millar JDH. Prevalence and familial incidence of disseminated sclerosis. Ulster Med f 1954;23(suppl. 2).

22 Kolmos $\mathrm{L}$, Bach E. Sources of error in registering suicide. Acta Psychiatr Scand 1987; Suppl 336(76):22-43.

23 Poser S, Kurtze JF, Poser W, Schlaf G. Survival in multiple sclerosis. f Clin Epidemiol 1989;42:159-68.

24 Stenager E, Knudsen L, Jensen K. Multiple sclerosis: The impact of physical impairment and cognitive dysfunction on social and spare time activities. Psychoter and Psychosom 1991;56:123-8.

25 Stenager E, Knudsen L, Jensen $\mathrm{K}$. The importance of occupational rehabilitation for the patient with multiple sclerosis. In: Jensen K, Knudsen L, Stenager E, Grant I, sclerosis. In: Jensen $\mathrm{K}$, Knudsen $\mathrm{L}$, Stenager $\mathrm{E}$, Grant I,
eds. Mental disorders and cognitive deficits in multiple sclerosis. London: John Libbey \& Co, 1989:203-7. 